\title{
Analysis and Thought on Status of Folk Art in Henan
}

\author{
Yelu Zhang \\ Henan Institute of Education, Zhengzhou, 450046, China
}

Keywords: Henan; folk art; realistic value; protection

\begin{abstract}
The Henan folk art penetrates in various aspects like the social production and living, daily necessities, customs, ritual, belief and taboo, being the living fossil of Chinese history and culture. In this paper, starting from the realistic value of Henan folk value, the author deeply analyzes the status of Henan folk art and proposes several countermeasures for protection.
\end{abstract}

\section{Realistic value of Henan folk art}

The Henan folk art works are of various forms, with high artistic quality and strong human interest, and this traditional cultural and artistic resource still has continuous vitality and extremely high realistic value till now, mainly reflected in the following four aspects:

(I) Practical value

Utilitarian is the main purpose of folk artistic work creation in the early period, especially for some craftworks with practical value in life, for example, embroidered shoes should both wear comfortable and look beautiful in appearance; blue and white porcelain jars can be used to fill things and also used for appreciation. Upon the efforts of countless generations of folk craftsmen, a beautiful form has been formed in the folk art, and presented in various aspects of life, for example, the folk paper cutting art in Henan can be associated with festivals, and this reflects its practical value and is also the main reason for inheritance till now. Another example is the perfume satchel art widely popular in Henan. Perfume satchel is generally woven with the colorful wires, with various vanillas in it, and its practical value is mainly reflected in parasite expelling and dispelling diseases. Besides, perfume satchel can also be used as the love pledge between lovers, and this manifests its aesthetic value, i.e. the organic unification between utilitarian and aesthetics, it is because of the existence of such value that the Henan folk art is endowed with "immortal life".

(II) Artistic value

At present, there are still a lot of primitive and traditional things reserved in Henan folk art, which reflect the simple aesthetic concept of Chinese nation. Most of the folk craftsmen take everything in the nature as the carrier and use their own wisdom and artistic talents for improvisation, when we feel the folk craftwork carefully, we can relax ourselves greatly both physically and mentally, our emotion can also be upgraded, and these are all closely associated with the artistic value of the folk art. The life habits in Henan reserve many oriental cultural atmospheres of the ancient $t$ times, and some painters combine these atmospheres with the organic artistic means and styles to form their unique painting style, and have created a lot of artistic works with rich national characteristics. Although the contents and forms of the folk art will be changed with time passing by, the artistic value contained in them is immortal.

(III) Tourism value

Tourism as the tertiary industry has been rapidly developed in recent years, thus driving the development of local economy. With the rising of tourism industry, not only the famous rivers and mountains have become the tourist attraction, various folk cultures have also been appreciated by the tourism enthusiasts, especially some folk craftworks have become the first choice for tourists in shopping. The development of tourism culture industry and relevant souvenirs make the folk artworks return to the realistic life again and endowed with certain tourism value. For example, Millennium City Park in Kaifeng, Henan re-mines and rescues the lost folk arts and exhibits them collectively after clearing. When touring in the park, tourists cannot only enjoy the Bian embroidery, wood plate new year pictures, sugar figures, dough figures, kites and the on-site performance other 
folk handcrafts, but also watch the custom performances like acrobatics, bird training and cock fighting, thus a lot of tourists are attracted, with tourism value manifested. So the Henan folk art has become an important tourism resource.

(IV) Cultural value

Folk art is one of the important parts of the national culture, deepening the researching on it is helpful to inherit and carry forward the national culture. Besides, the folk art also involves in many fields related with people's life, and it can be said to be an expression form of folk culture. The most outstanding characteristics of Henan folk art are being simple and natural, and this is also the main reason why it is deeply loved by people, for example, the "mud dog" in Huaiyang, Henan, the value of which is centrally reflected in the national connotation. Although the change of times has diluted the original function of "mud dog", the cultural temper it contains is not diluted with time, on the contrary, it is strengthened.

\section{Analysis on status of Henan folk art}

Most of the folk artworks in Henan are closely associated with the folk legend, the artworks are mainly made of stone ink slab, animal skin, lacquer, wood, fabric, bamboo weaving, new year picture, marble and jade etc, with contents covering longevity and health, flourishing family, auspiciousness, wealth and harmony, being the typical representative of the traditional Chinese culture. For example, one of the four famous ink slabs Dengni Ink Slab in the Chinese history, "masterpiece of world art" Nanyang poker picture, Kaifeng Bian embroidery, a miracle in the Chinese embroidery, Zhuxianzhen wood plate new year picture, the pioneer of Chinese wood plate new year picture, Junci porcelain of various colors, Nigugu, the living fossil of regional custom culture etc., which are all the precious cultural relics in Henan. With the development of times and increasingly strong commodity awareness, the artistic functions and social functions of some folk arts have been forgotten by people, making the Henan folk art suffer from a gloomy survival situation, mainly reflected in the following:

(I) The categories of folk art are gradually declined

According to the overall condition of folk art category in China, although most of the categories still exist, compared with the heyday in the past, some categories have been gradually declined, which has a great influence on the inheritance of folk art categories. The main reasons causing this problem can be concluded as follows: first, there is a serious aging trend of folk craftsmen. According to the investigation statistics of relevant department in Henan, the inheritors of intangible cultural relics in Henan have an age of about 64 years old, these nearly 60 years account for $70 \%$ of the total population and the oldest is 109 years old, so there is obvious aging trend for the folk craftsmen. Second, the number of ordinary practitioners in the categories of folk art has been decreased sharply, some categories have been lost, for example, the mud toy in Luoyang, Henan, which is a folk painted sculpture with extremely local characteristics, has no inheritor at present; another example is the shadow play, which was throughout Henan in the early period, but there are fewer and fewer folk teams that can perform shadow play; only several operators operate the wood new year picture in Zhuxianzhen, and there are only 5 or 6 operators of mud dog in Huaiyang. As stated above, it has become an undisputed fact that the folk artistic categories in Henan have been declined, if the situation is further worsened, most of these categories will disappear thoroughly after dozens of years.

(II) The traditional technology of folk has been gradually lost

The rapid development of society has greatly impacted the folk art tradition. At present, the materials used in some artistic categories have disappeared, and for some materials, as it is time costing and strenuous in making, the practitioners are unwilling to use them, causing that most of the traditional technologies have been gradually lost. For example, the black in the wood plate new year picture of Zhuxianzhen was made of paste by adding pine soot and water, after natural feminization, appropriate water was added for grinding with stone mill, and finally filtered with abrasive cloth for storage, when printed in paper, it would present black and bright luster, without wrinkling. As this technology is relatively complicated, seldom people have used it, and generally 
replace it with the ordinary ink in painting. In addition, the process of new year picture painting has also decreased, for example, the colors "water red" and "orange" are not printed. At present, in the whole Zhuxianzhen, there is only 1 workshop making wood plate new year picture according to the traditional technology. Another example is Bian embroidery, the traditional Bian embroidery is made by hand, with meticulous and vivid characteristics, but the situation of replacing hand making with computer has appeared.

(III) Rough manufacturing of folk artworks

At present, there is an extremely serious situation of rough manufacturing in the folk artworks of Henan, the reasons for this are mainly as follows: first, the driving of benefit. The industrialization of Henan folk art brings certain economic benefit. In appearance, the industrialization promotes the development of folk art and increases profit substantially. Driven by this factor, some inheritors are no longer devoted to researching the works and improving their quality, but try every best to obtain profit, causing the rough manufacturing of a lot of artworks. Second, the reasons of inheritors themselves. According to relevant investigation, most of the inheritors of intangible cultural heritages in Henan graduate from primary school or junior middle school. As they do not receive higher education, they do not understand the traditional culture and master the skill in place, causing the manufacturing of artworks, for example, the errors appearing in Zhuxianzhen new year picture Shouzhou City, the opera Qin Qiong Challenge and "Guo Ju Burying Son".

(IV) Insufficient investment to inheritance of folk art

The folk art is a kind of cultural relic needing protection, while the key to protect the folk art is to protect the inheritors. Although the local government has strengthened investment in this aspect, overall, there are still many shortcomings, and many categories are not subsided. At the same time, due to no market for some categories, the inheritors often fall into the awkward situation, in order to support the family, they have to change their post, for example, the inheritor of mud dog $\mathrm{Xu}$ Chuanke in Huaiyang, Henan, because of very few sales of works, has to go outside for odd job to sustain livelihood, and the making of mud dog becomes his avocation; another example, is "mud monkey Zhang" in Henan, although he has certain status in the folk art industry, and his works have obtained many awards, the income of selling mud money is very limited, so he has to transfer to calligraphy and painting creation, and uses the income of selling calligraphy and painting works to continue his mud monkey creation. There are still many such cases, it they are not solved very well, the inheritance will be influenced.

\section{Countermeasures to strengthen protection of Henan folk art}

(I) Create a good protection environment of folk art

The inheritance and development of Henan folk art should depend on the joint efforts of government, experts, scholars and inheritors, it is suggested to establish the long-term mechanism for inheritance of folk artistic relics. Experts and scholars should provide reasonable suggestions for the development of Henan folk art, improve the grade of folk artworks, expand the horizon of inheritors and ensue that the government is effectively utilized. Meanwhile, establish intangible cultural relic files, image and video database and digital museum, so that the whole society can understand the folk art of Henan, thus laying a mass foundation for the inheritance of folk art. In addition, it is also required to use more media to convey relevant information on creation of folk artworks and improve the cultural protection awareness of the whole nation.

(II) Make great efforts to promote industrialization development of folk art

In order to better convey and develop Henan folk culture, it is required to take the road of industrialization development, implement brand strategy with Henan characteristics and increase the social value and economic value of folk artworks. First, Henan should highlight the local characteristics, establish production and sales enterprises surrounding the development of folk artworks to specially dedicated to the production and sales of folk artworks, manage the folk art industry in a unified manner and promote the inheritance of folk art in modern society. Second, while strengthening the folk art industry, strengthen the protection and utilization of folk art resources, pursue economic benefit reasonably on the basis of cultural heritage, and provide fund 
support for the sustainable development of folk art.

(III) Mine the potential value of folk art

There are various forms of folk arts in Henan, with perfect modeling and pattern and strong transitional cultural atmosphere. In order to strengthen the development of Henan folk art resources, it is required to blend the folk art into design, animation, network game, advertisement, tourism and other modern cultural industries reasonably, always root it into the essential concept, creative method and modeling means of folk art, take the modern cultural industry as an important platform to communicate the Henan folk culture and continuously expand the influence of folk art. Meanwhile, Henan should seize the opportunity of local culture and mine the folk art resources to shape the folk art culture image.

(IV) Improve folk art inheritor mechanism

At present, Henan has mastered relevant information of the intangible cultural heritage inheritors. To this end, it is required to establish and improve the folk art inheritor mechanism by taking advantage of this opportunity, register and file the inheritors to form detailed list information of inheritors and avoid the dilemma of extinction in the protection and development of cultural art. Henan government should invite experts to strictly evaluate and approve the inheritor applicants, ensure that they conform to relevant assessment criteria in material, technology and quantity etc. and prevent those for benefit to sneak into the team of inheritors. Meanwhile, Henan government should organize experts to recheck the qualification of inheritors, in case of vulgar and rough works, the inheritors should be removed from the title.

\section{Conclusion}

Henan folk culture has inherited till now with its special artistic styles. It is not only an important part of the traditional art, but also the image carrier of Henan custom culture, with quite unique artistic aesthetic value, and the existence of this value make Henan folk culture widely concerned by all circles of the society, and it is extremely important to effectively develop and reasonably protect it. Therefore, it is required to inherit in protection and develop in innovation and return the folk art to the "folk really", only in this way can it be inherited continuously.

\section{Acknowledgments}

This paper is the staged achievements of Henan provisional philosophical and social science planning project "Research on inheritance and development of Henan folk art in modern education" (project No. 2014BYS010)

\section{References}

[1] Xia Wanqun, Chen Jiangfeng, History, Status and Rescue Protection of Intangible Cultural Relics in Henan [J] Henan Social Science, 2012 (7)

[2] Li Yanfeng, On Folk Belief and Folk Artistic Modeling-Take "Mud Dog" in Huaiyang, Henan as an Example [D], Henan University, 2010.

[3] Wang Shengxuan, Gao Min, Inheritance, Variation and Development of Henan Folk Plastic Toys [J] Journal of Ankang University, 2010 (6)

[4] Qin Yanpei, Development of Tourism Commodity Quality of Intangible Cultural Relics [J] Journal of Zhengzhou University (philosophy and social science edition), 2012 (4)

[5] Huang Xiping, A Miracle in the Long History-Discussion on Artistic Value of Henan Folk Dough Plastic [J] Journal of Zhongzhou University, 2012 (4)

[6] Hu Qinghong, Inheritance and Development of Folk Art in the Background of Market Economy [J], Journal of Jilin Teachers' Institute of Engineering and Technology, 2012 (12)

[7] Peng Xinqin, Ge Tiantian, Discussion on Digitalized Protection of Folk Art [J] Journal of Chifeng University, 2014 (3) 